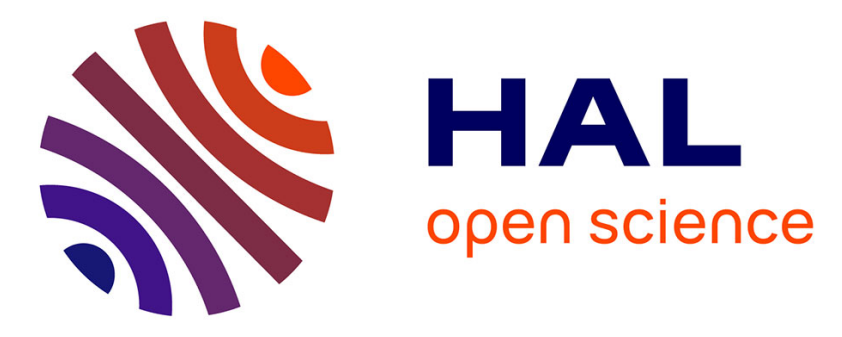

\title{
Applying Massively Parallel Computing to Multi-Scale Ka Dual-Band Transmit-Array Analysis using FETI-2LM
}

Andre Barka, Sergio A Matos, Jorge R. Costa, Carlos A Fernandes, Hassan Chreim

\section{To cite this version:}

Andre Barka, Sergio A Matos, Jorge R. Costa, Carlos A Fernandes, Hassan Chreim. Applying Massively Parallel Computing to Multi-Scale Ka Dual-Band Transmit-Array Analysis using FETI2LM. IEEE Journal on Multiscale and Multiphysics Computational Techniques, 2020, 5, pp.235-244. 10.1109/JMMCT.2020.3033846 . hal-03010252

\section{HAL Id: hal-03010252 https://hal.science/hal-03010252}

Submitted on 17 Nov 2020

HAL is a multi-disciplinary open access archive for the deposit and dissemination of scientific research documents, whether they are published or not. The documents may come from teaching and research institutions in France or abroad, or from public or private research centers.
L'archive ouverte pluridisciplinaire HAL, est destinée au dépôt et à la diffusion de documents scientifiques de niveau recherche, publiés ou non, émanant des établissements d'enseignement et de recherche français ou étrangers, des laboratoires publics ou privés. 


\title{
Applying Massively Parallel Computing to Multi-Scale Ka Dual-Band Transmit-Array Analysis using FETI-2LM
}

\author{
André Barka, Sérgio A. Matos, Member, IEEE, Jorge R. Costa, Senior Member, IEEE, Carlos A. Fernandes , \\ Senior Member, IEEE, Hassan Chreim
}

\begin{abstract}
Transmit-arrays (TAs) are a popular cost-effective solution for high-gain antennas at millimeter waves $(\mathrm{mmW})$. The design of these antennas relies on the fine tuning of the subwavelength unit-cells that compose the aperture. The intricacy of the unit-cells increases as new features are implemented, such as dual-band operation and wide-angle beam steering, making this antenna even more computationally challenging. In this work, a high gain (25 dBi @ $20 \mathrm{GHz}$ and $28 \mathrm{dBi} @ 30 \mathrm{GHz})$ multiscale Ka dual-band TA for beam-steering applications is analyzed using a massively parallel implementation on multicores clusters of the Finite Element Tearing and Interconnecting method, with a two Lagrange Multiplier (FETI-2LM) technique.

The main contribution of this work is the implementation of 3D non-periodic grids with sub-domains of different scales, that is suitable for proper modelling of different regions of the antenna (horn feed, lens cells, air region). An automatic batch file procedure is proposed for the TA meshing, allowing the limited set of constitutive unit-cells of the TA to be meshed separately. Additionally, we are using a block-Krylov strategy to efficiently capture the TA beam-steering capability, without restarting from scratch the interface problem for each feed position. Since other Finite Element Method (FEM) results were not accessible due the size of the problem, the FETI-2LM numerical results provided in this work are compared with other MultiLevel Fast Multipole Method (MLFMM) [1] and Transmission Line Modeling Method (TLM) [2] of CST Microwave Studio solvers, as well as with the measured results of the corresponding $\mathrm{Ka}$ dual-band prototype. The computational infrastructure has been used only a fraction of its capacity. Therefore, a much higher gain design (40 dBi) can be assessed, opening a new realm of applicability of TAs in the space segment usually occupied by reflector-based solutions.
\end{abstract}

Index Terms-Finite Element Tearing and Interconnecting (FETI), Finite Element Method (FEM), Domain Decomposition, Krylov spaces, Ka-band transmit-array, GID pre-processor.

\section{INTRODUCTION}

\footnotetext{
${ }^{1}$ Part of the research leading to the numerical results has received funding from the French Ministry of Defense (DGA/MRIS) through a DGA/ONERA ERE convention (2016.60.0003.00.470.75.01). DDM Simulation results have been obtained using HPC resources from GENCI (Grant c2014109083).

A.Barka is with the French Aerospace Laboratory-ONERA-DEMR, MidiPyrenees, Toulouse Center, and also with the Universite de Toulouse, 31000 Toulouse, France (e-mail:andre.barka@onera.fr)

S. A. Matos and J. R. Costa are with the Instituto de Telecomunicações, Instituto Superior Técnico, Universidade de Lisboa, 1049-001 Lisbon, Portugal, and also with the Departamento de Ciências e Tecnologias da Informação, Instituto Universitário de Lisboa (ISCTE-IUL), 1649-026 Lisbon, Portugal (e-mail: sergio.matos@iscte.pt).

C. A. Fernandes is with the Instituto de Telecomunicações, Instituto Superior Técnico, Universidade de Lisboa, 1049-001 Lisbon, Portugal.

H. Chreim is with 3DS-SIMULIA, 3DS Paris Campus, 78140 VélizyVillacoublay FRANCE
}

$\mathbf{K}$ A-band high-gain antennas providing broadband access services are required for installation on High Throughput Satellites (HTS) and High Altitude Platforms (HAPs). Recent works show that transmit-arrays can also be a viable solution for Satcom On The Move (SOTM) ground terminals in the Ka-band [3], [4]. In [3] a simple mechanical beam-steering antenna concept has been proposed, in which high-gain $(28$ $\mathrm{dBi})$ is conciliated with wide-angle elevation beam-steering $\left(-50^{\circ}, 50^{\circ}\right)$ by a relative in-plane translation of a thin offset flat lens above a stationary primary feed. The full azimuth coverage is then obtained by a $360^{\circ}$ rotation of the TA. In [4], a dual-band version (20 and $30 \mathrm{GHz})$ of the TA was developed, which required additional complexity of the unitcell design. The working principle of this antennas is shown in Fig.1. In the single and dual-band cases, the electric size (at $30 \mathrm{GHz}$ ) of the aperture is $20 \lambda \times 15 \lambda$ and it comprises several thousand of unit-cells (4524 in [3] and 2352 in [4]) arranged in a non-periodic pattern to collimate and offset the incoming spherical-wave. Although full-wave evaluation of these antennas using commercial solvers is possible, it can take several hours, or even days, to complete, even using high-end state-of-the-art workstations. The optimization of the antenna is quite challenging. Several approximate methods can be applied, based on a mix of analytical modeling and full-wave electromagnetic simulations [5], Physical Optics and Geometrical Optics (PO/GO) techniques [6] and even equivalent dielectric homogenization techniques [7]. However, fullwave simulations of the real structure cannot be removed from the design process, especially when a complex fabrication process is involved. One such example is the sensitive analysis of manufacturing imprecisions, which cannot be undertaken using approximate methods. Moreover, fast and accurate evaluations are required to properly optimize the TA. We should stress that the TA design is intrinsically approximate, since it extrapolates the periodic behavior of the unit-cells to the non-periodic background of the TA. This is usually referred to as the quasi-periodic approximation [8], which does not hold for the regions of the lens where fast phase variations occur. Finally, when higher gains are required, as in the case of Geosynchronous Equatorial Orbit (GE0) satellite terminals (40 dBi) [9], all of the aforementioned problems are exacerbated and the solution is not easily accessible with commercial softwares as CST Microwave Studio and HFSS even on powerfull workstations with large memory resources. We should stress that, a $40 \mathrm{dBi}$ gain cannot be achieved by simply scaling-up a 
given $30 \mathrm{dBi}$ TA design [10], since aberrations and fast phase variations also scale up. The application of massive parallel computing to TAs is therefore very relevant for this active field of research.

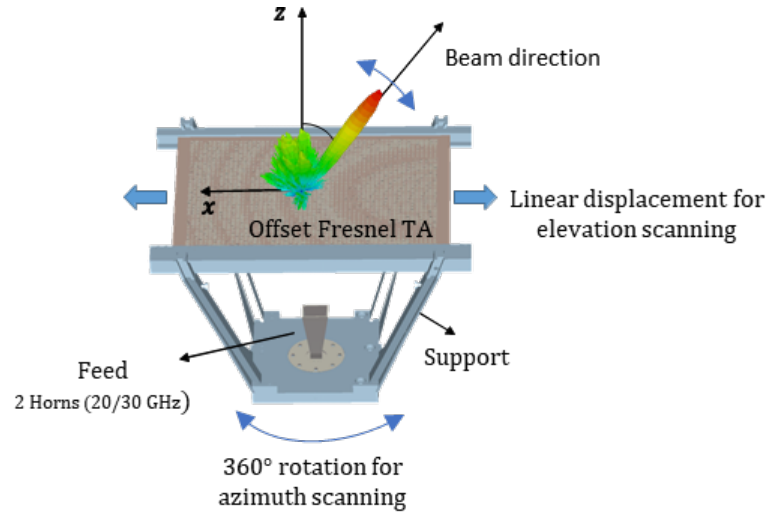

Fig. 1. TA beam-steering antenna concept implemented in [2] for dual-band operation. Focal distance between the horn and the lens $\mathrm{F}=100 \mathrm{~mm}$, length along the $\mathrm{X}$ axis $D_{a x}=196 \mathrm{~mm}$, width along the $\mathrm{Y}$ axis $D_{a y}=147 \mathrm{~mm}$
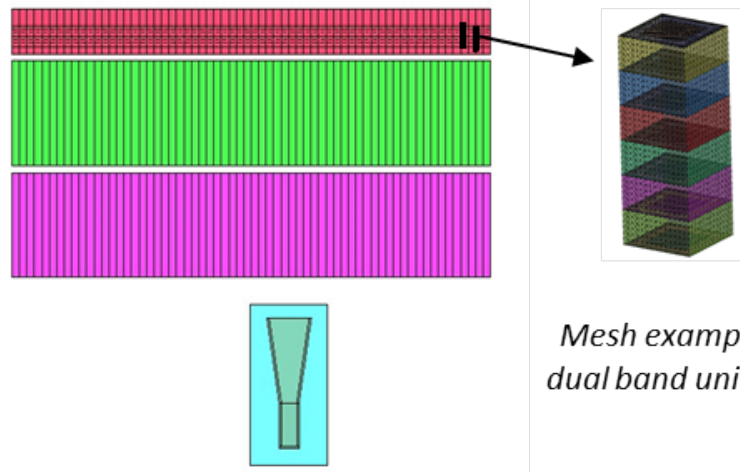

Mesh example of a dual band unit cell

Fig. 2. Exploded image of the TA domain decomposition (from bottom to top: horn (cyan), empty (purple and green), TA (red))

The objective of this work is to evaluate the potential of the FETI-2LM domain decomposition method [11] [12] for the simulation of large scale transmit-arrays such as those described in Fig. 2 and Fig. 1 on massively parallel clusters using MPI programming. This kind of resources is not farfetched for TA simulations and available High Power Computing resources in France and Europe can be used for this purpose. In France the "Grand Equipement National de Calcul Intensif" (GENCI) consortium provides computing hours to research organizations within the framework of innovative projects [13]. In Europe, the Partnership for Advanced Computing in Europe (PRACE) provides access to world class HPC computing resources [14]. Recent results we obtained within the context of ultra large band microwave materials [15], [16], using the FETI-2LM technique [11] [12], have been completed in this work for antenna gain simulations. TA translation over fixed feed is equivalente to fixed TA with feed in multiple positions. Therefore, a multi-source FETI-2LM formulation [12] is used to address this TA simulation. The iterative resolution efficiency of the interface problem for assembling the local solutions coming from the overall sub-domains is not favorable due to linearly independent near fields of the different sources (the incident fields on the lens for several feed positions are clearly different), even with standard Krylov recycling techniques. To remedy this problem we used the efficient block-Krylov algorithms initially developed in [12].

The main particularity of our implementation remains in the fact that we do not mesh the initial global domain before the resolution of the electromagnetic problem. As a consequence a mesh splitter tool like METIS [17] is not necessary to decompose the large scale initial mesh into subdomains, as was done for example for array antennas covered by a radome in [18]. Our method is general and efficient by introducing 3D multi-scale non-periodic grids with subdomains that are not necessarily of the same size (horn feed, lens unit-cells and empty sub-domains described in Fig. 2 and Fig. 3). Each sub-domain of our decomposition belonging to a limited set of unit-cell meshes, is locally meshed with an automatic procedure of the GID preprocessor [19] based on GID batch files and $T c l$ scripts [20]. In this way, very complex TA antennas including very fine details (width of loop metallizations comprised between $\frac{\lambda}{200}$ and $\frac{\lambda}{50}$ ) are efficiently represented with only a few local meshes. The interest of this strategy is that since the method is implemented on parallel machines, each computation core is allocated exclusively to a sub-domain (elementary cell of the TA). Then, with at least $4 \mathrm{~GB}$ of memory allocated exclusively to a sub-domain (elementary cell of the TA), relatively fine meshes can be implemented easily in each sub-domain. This methodology makes unnecessary the sometimes very slow adaptive mesh refinement techniques.

The paper comprises the following sections. Section II presents briefly the implementation of a total field FETI2LM formulation with block-Krylov multi-source algorithms to speed-up the beam-steering simulations of TAs and describes an effective meshing strategy for fundamentally nonperiodic applications with sub-domains of different scales. Section III completely describes the geometry of the $30 \mathrm{dBi}$ dual-band TA, as well as cross comparison of FACTOPO (FETI-2LM) simulation results with CST simulation results (TLM and MLFMA) and experimental results. Finally, section IV discusses the efficiency of parallel computation using the new FETI-2LM implementation and gives, by extrapolation, an estimation of the memory and number of computing cores required for a $40 \mathrm{dBi} \mathrm{TA}$ simulation, following a recent improvement of the FETI-2LM preprocessing for space radar surveillance [21].

\section{FETI-2LM IMPLEMENTATION FOR TRANSMIT-ARRAY SIMULATIONS}

The Finite Element Method (FEM) is one of the most successful frequency domain computational methods for electromagnetic simulations [22] of antennas or microwave circuits engineering applications. For computationally challenging TA applications, FEM method requires the solution of problems with billion of unknowns, that are very difficult to solve with 

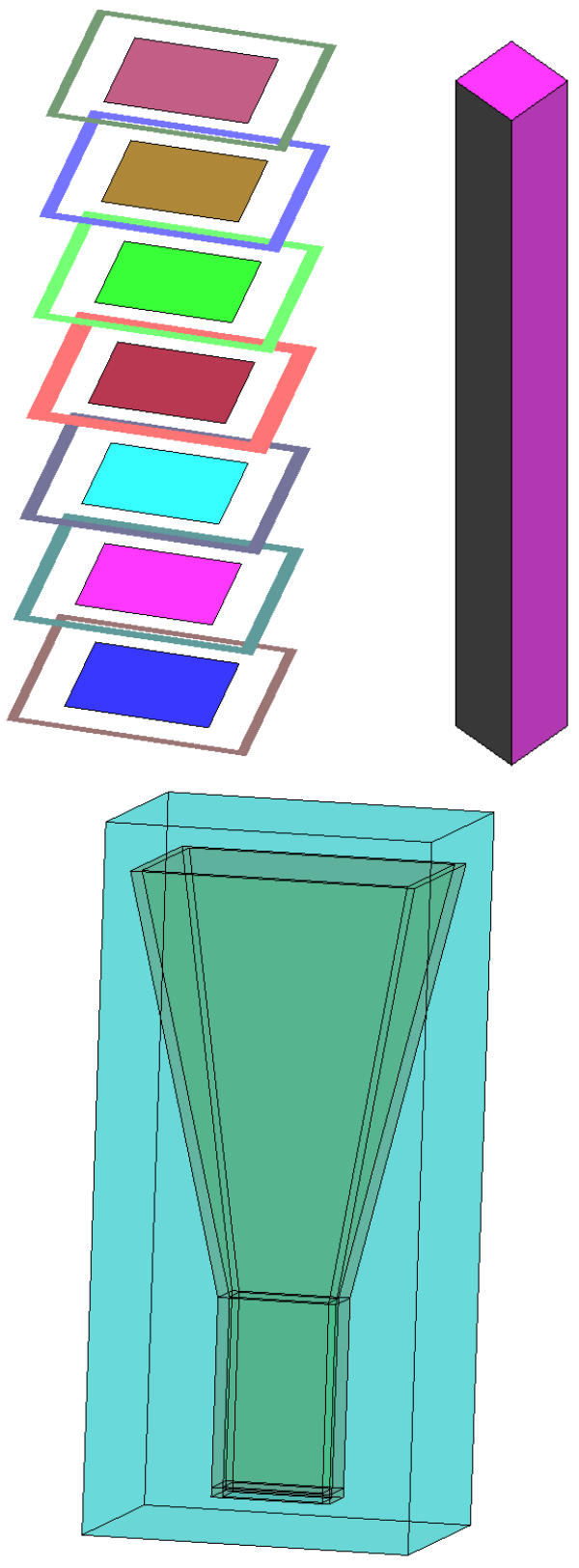

Fig. 3. Three types of sub-domains: lens sub-domain (left side), empty subdomain (center), horn sub-domain (right side)

a single computational domain using commercial softwares as CST Microwave Studio [23] or HFSS [24]. Such simulation problems can be very difficult to solve, especially when the problems of interest involve multi-scale geometries, with very small details compared to the wavelength, are used in Ka band transmit-array applications. From this perspective, the FETI2LM method proposed to solve the Maxwell equations [11], [25], [26], is splitting the initial computational domain into non overlapping sub-domains. Finite Element solution of the local problems are obtained first with the Intel PARDISO direct solver [27]. Then, 2 Lagrange Multipliers are introduced to impose tangent field continuity at the interfaces of the subdomains, and the reduced problem at the interfaces is solved with an iterative ORTHODIR method [28].

The scanning of the beam is obtained by linear translation of the primary source (here the horn placed under the TA). Consequently, the analysis of a large number of beams , requires efficiently computation of multi-source problems with the FETI-2LM iterative method. Once the interface problem was solved with the Krylov space method for the first source (first position $a_{0}$ of the primary feed under the TA as described in Fig. 1), a set of search direction vectors was built and can be stored in memory. These direction vectors obtained for all the successive primary feeds investigated under the TA provide a natural set of vectors to be used for implementing a preconditioner which decreases the number of iterations during ORTHODIR iterations. With this technique, the number of new iterations required for each new feed position decreases dramatically. It is well established that this recycling technique is very efficient for linearly dependent sources (plane wave excitations for example) as discussed for example in [12] where an acceleration of the calculation time by a factor of 115 is obtained. Unfortunatly, it is not the case for TA applications for which the translation of the primary feed above the TA implies the sources to be linearly independent resulting in a much less rapid convergence of the recycling algorithm. To fix this problem, we used the block-Krylov recycling [12], whose main consequence is to improve the parallel efficiency of the method. The idea consists in solving the successive problems in blocks, with a few right-hand sides (typically 10-20) solved at the same time. This technique consists in computing several search directions at each iteration of the interface problem and all of the search directions of the block are used for all of the right-hand sides. The efficiency of the block-Krylov recycling technique allowing an acceleration by a factor 11 of the simulation has been demonstrated in section III Tab. X for the calculation of the complete $\mathrm{Ka}$ dual-band transmit-array proposed in this work.

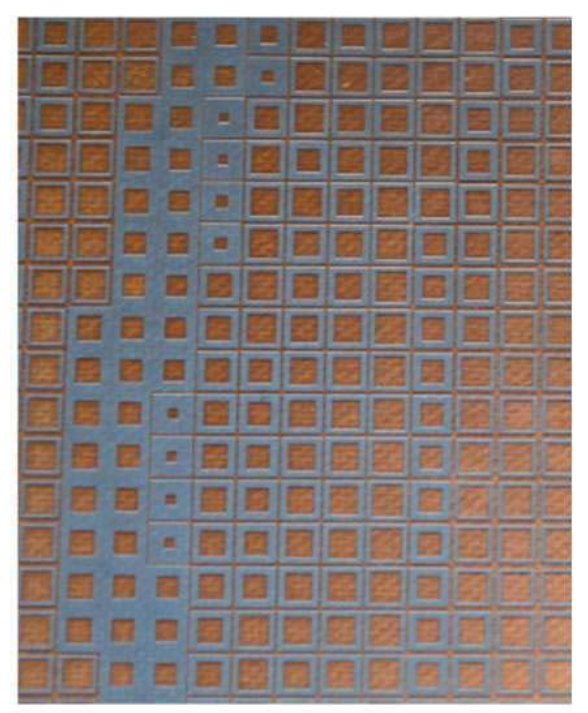

Fig. 4. Zoom on lens unit-cells to be meshed (front view) 


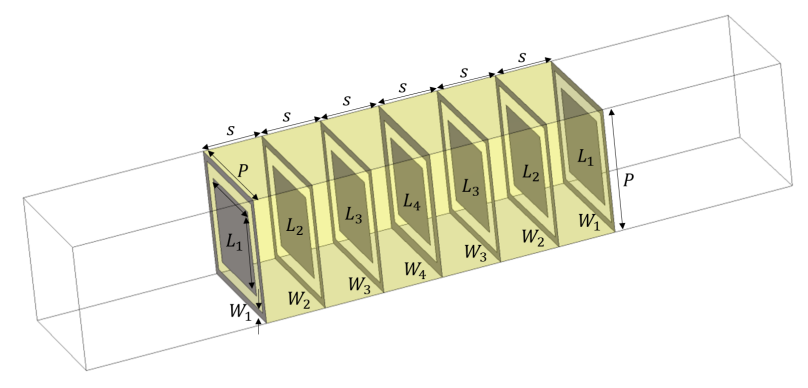

\begin{tabular}{|c|c|c|c|c|c|c|c|c|c|}
\hline$\phi_{f_{1}}\left({ }^{\circ}\right)$ & $\phi_{f_{2}}\left({ }^{\circ}\right)$ & $\begin{array}{c}W_{1}=W_{7} \\
(\mathrm{~mm})\end{array}$ & $\begin{array}{c}W_{2}=W_{6} \\
(\mathrm{~mm})\end{array}$ & $\begin{array}{c}W_{3}=W_{5} \\
(\mathrm{~mm})\end{array}$ & $\begin{array}{c}{ }_{5} W_{4} \\
(\mathrm{~mm})\end{array}$ & $\begin{array}{l}L_{1}=L_{7} \\
(\mathrm{~mm})\end{array}$ & $\begin{array}{l}L_{2}=L_{6} \\
(\mathrm{~mm})\end{array}$ & $\begin{array}{l}L_{3}=L_{5} \\
(\mathrm{~mm})\end{array}$ & $\begin{array}{c}L_{4} \\
(\mathrm{~mm})\end{array}$ \\
\hline $0 / 1$ & 0 & 0 & 0,05 & 0,05 & 0 & 1,6 & 2 & 1,5 & 1 \\
\hline 12 & 12 & 0 & 0,05 & 0,05 & 0 & 2 & 1,9 & 0 & 0 \\
\hline 40 & 51 & 0 & 0,1 & 0,1 & 0 & 2,2 & 1,6 & 0 & 0 \\
\hline 50 & 69 & 0 & 0,1 & 0,1 & 0 & 2 & 1,6 & 0 & 0 \\
\hline 55 & 96 & 0,2 & 0,2 & 0,2 & 0,2 & 2,4 & 2,4 & 2,3 & 2.4 \\
\hline 87 & 142 & 0,2 & 0,2 & 0,2 & 0,3 & 2,4 & 2,3 & 2,3 & 2,2 \\
\hline 103 & 172 & 0,2 & 0,2 & 0,2 & 0,3 & 2,4 & 2,3 & 2,2 & 2,1 \\
\hline 155 & 240 & 0,2 & 0,2 & 0,2 & 0,3 & 2,4 & 2,2 & 2 & 2 \\
\hline 196 & 311 & 0,15 & 0,2 & 0,2 & 0,3 & 2,1 & 2 & 2 & 2 \\
\hline 235 & 359 & 0,15 & 0,2 & 0,2 & 0,3 & 1,9 & 2 & 1,9 & 2 \\
\hline 277 & 396 & 0,05 & 0,05 & 0,05 & 0 & 2,4 & 2,4 & 2,4 & 2,4 \\
\hline 291 & 405 & 0,1 & 0,05 & 0,05 & 0 & 2,5 & 2,4 & 2,4 & 2,3 \\
\hline 314 & 455 & 0,1 & 0,05 & 0,05 & 0 & 2,5 & 2,3 & 2,4 & 2,1 \\
\hline 341 & 489 & 0,1 & 0,1 & 0,05 & 0 & 2,3 & 2,3 & 2,3 & 2,3 \\
\hline 341 & 489 & 0,1 & 0,1 & 0,05 & 0 & 2,2 & 2,2 & 2,2 & 2,2 \\
\hline 411 & 596 & 0,1 & 0,1 & 0,1 & 0,1 & 2.2 & 2.1 & 2.2 & 2.1 \\
\hline 428 & 621 & 0,1 & 0,1 & 0,1 & 0,1 & 2,1 & 2,1 & 2,1 & 2,1 \\
\hline 456 & 701 & 0,1 & 0,05 & 0,05 & 0,1 & 2,4 & 1,8 & 1,2 & 2 \\
\hline 476 & 718 & 0,1 & 0,05 & 0,05 & 0,1 & 1,9 & 1,8 & 1,9 & 1.7 \\
\hline 501 & 756 & 0,1 & 0,05 & 0,05 & 0,1 & 2,4 & 1,2 & 1,2 & 1,7 \\
\hline 531 & 776 & 0,1 & 0,05 & 0,05 & 0,1 & 2,3 & 1,2 & 1,2 & 1,3 \\
\hline 559 & 819 & 0,1 & 0,05 & 0,05 & 0,1 & 2 & 1,2 & 1,2 & 1,2 \\
\hline 599 & 886 & 0,05 & 0,05 & 0,05 & 0.05 & 1 & 0,8 & 1 & 0,8 \\
\hline 596 & 876 & 0,1 & 0,05 & 0,05 & 0,1 & 1,4 & 0,4 & 1,4 & 0,4 \\
\hline 608 & 897 & 0,05 & 0,05 & 0,05 & 0.05 & 0.8 & 0 & 1 & 0,8 \\
\hline 584 & 895 & 0,05 & 0,05 & 0,05 & 0.05 & 0.8 & 0 & 1 & 0 \\
\hline 630 & 960 & 0 & 0 & 0,05 & 0 & 1,7 & 2,5 & 1,9 & 1,1 \\
\hline 645 & 969 & 0 & 0 & 0,1 & 0 & 1,7 & 2,5 & 1,9 & 1,1 \\
\hline 665 & 967 & 0 & 0,05 & 0,05 & 0 & 1,7 & 2,5 & 1,9 & 1,1 \\
\hline 704 & 1050 & 0 & 0,05 & 0,05 & 0 & 1,8 & 2 & 1,7 & 0.9 \\
\hline
\end{tabular}

Fig. 5. Dual-band unit cell (geometry of the 30 lens cells)

The complete mesh of the dual-band TA (Figure 2), which is very tricky to achieve and requires considerable memory resources, is therefore not built into our simulation methodology. The TA being non-periodic, a single domain pre-treatment step would be long and difficult to implement even with an automatic mesh splitter such as METIS [17]. The alternative strategy proposed in this work makes it possible to virtually build the mesh of the complete TA with only 3 types of subdomain meshes ("lens unit cell", "empty unit-cell" and "horn" described on Fig. 3). As a consequence, our implementation of the FETI-2LM method only requires that the mesh has a reasonable size for each sub-domain. Each unit-cell of the TA has been designed in [4] to provide a phase correction at position $(x, y)$ defined by:

$$
\Phi_{\text {lens }}(x, y)=k_{0} \sqrt{x^{2}+y^{2}+F^{2}}-k_{0} x \sin \alpha_{0}
$$

where $F$ is the focal distance and $\alpha_{0}$ is the zenithal beam angle when the feed is at the central position $(x=0, y=0)$. They comprise metallized layers of concentric squared patches and strip loops printed on substrate layers as described in Fig. 3 and Fig. 5. The in-plane TA is designed with a set of $N_{\text {elem }}=30$ elementary cells populating the dual-band transmit-array. The geometry and mesh is generated automatically via batch files that are executed by the GID software (Fig. 4). The batch files used to create the geometry are interfaced to an Excel table giving the geometric dimensions involved in the $N_{\text {elem }}=30$ cells (squared patches and strip loops geometrically described on Fig. 5 ). Finally, a Fortran script is interfaced with another Excel table (Tab. I) containing the position $(x, y, z)$ and type of each of the $N_{\text {TAcells }}=2352$ sub-domains of the complete TA to completely populate the TA by creating $N_{\text {elem }}$ GID batch-files. The $N_{\text {elem }}$ local meshes are then processed with short $T c l$ [20] script called in the command line of the GID preprocessor that launches the geometry and mesh batch files. In summay, the simulation strategy used is as follows:

TABLE I

STRUCTURE OF THE SHIFT FILE DESCRIBING THE POSITION AND GEOMETRY TYPE (FROM 1 TO 30) OF EACH OF THE 2352 IN-PLANE SUB-DOMAINS

\begin{tabular}{|l|c|c|c|c|}
\hline Sub-domain & Type & $\mathbf{x}$ & $\mathbf{y}$ & $\mathbf{z}$ \\
\hline 1 & 9 & -0.097 & 0.072 & 0.0 \\
\hline$\ldots$ & $\ldots$ & $\ldots$ & $\ldots$ & $\ldots$ \\
\hline 2352 & 6 & 0.096 & -0.072 & 0.0 \\
\hline
\end{tabular}

- Step 1: Design and optimization of the $N_{\text {elem }}=30$ unitcell geometry with CST Microwave Studio [23]

- Step 2: Automatic mesh generation of the $N_{\text {elem }}=30$ elementary unit-cells with the GID pre-processor [19]

- Step 3: Assignment of the $N_{\text {elem }}=30$ elementary mesh cells populating the lens to the sub-domains and calculation cores through Tab. I

- Step 4: FETI-2LM simulations using massively parallel clusters

- Step 5: Extraction of the radiation patterns of the TA

\section{Simulation RESUlTS OF THE MULTI-SCALE DUAL-BAND TRANSMIT-ARRAY}

This transmit-array simulation test case was proposed as part of the ISAE-2018 electromagnetic workshop on radar signatures and the geometry is given through STEP files that can be downloaded from the ISAE website [29]. In order to cross-check the FETI-2LM results, several electromagnetic solvers of the CST Microwave Studio tool have been used: the iterative MultiLevel Fast Multipole Method (MLFMM) [1] and the Transmission Line Modeling Method (TLM) [2]. A FEM solution, to be compared with FETI-2LM solution, could not be obtained with the CST solver, due to the large size of the TA problem (few billion unknowns) when solved with a single domain in its current non parallelized version. The objective is not to compare the intrinsic performances of these methods because the simulations could not be done on the same computer. The objective is only to recall their particularities for these TA calculations and to give some trends on the memory occupation, the computing times as well as their level of parallelization. Remember that the frequency domain FETI2LM and MLFMM methods can use very effective strategies 
for applications with multiple sources ( [30], [12]). This is not the case with the TLM method where the whole simulation must be repeated completely for each new position of the primary source. On the other hand, the TLM time domain method is very effective to solve the problem on a broad frequency band.

The dual-band TA designed and detailed in [4] operating at $20 \mathrm{GHz}$ and $30 \mathrm{GHz}$ is composed of 2352 unit-cells. The 30 dual-band constitutive unit-cells (Fig. 5) designed in [4] are properly distributed throughout the aperture to provide beam collimation. These unit-cells are composed of seven metallized layers of concentric squared patches and strip loops printed on six Rogers Duroid 5880 substrate layers (Tab. II). The thickness of each dielectric layer is $\mathrm{s}=1.617 \mathrm{~mm}$ and the in-plane width of the unit-cell is $\mathrm{P}=3.5 \mathrm{~mm}$. The dimensions of the metallization patterns of each layer (in $\mathrm{mm}$ ) can be found in Fig. 5 and Tab. II. One can observe that the width $W_{j}$ of the loop metallization is comprised between $\frac{\lambda}{200}$ and $\frac{\lambda}{50}$ while the width $L_{j}$ of the patches is comprised between $\frac{\lambda}{25}$ and $\frac{\lambda}{4}$ at $30 \mathrm{GHz}$ (Tab. III). The unit-cell details are then very small compared to the TA aperture at $30 \mathrm{GHz}(20 \lambda \times$ $15 \lambda)$ and the total calculation volume $(18 \lambda \times 20 \lambda \times 15 \lambda)$ making the problem very difficult to solve.

TABLE II

DUAL-BAND UNIT-CELL

\begin{tabular}{|l|c|}
\hline Rogers Duroid 5880 & $\epsilon_{r}=2.2$ \\
\hline Dielectric permittivity & $\tan \delta=0.0009$ \\
\hline Dielectric loss tangent & $\begin{array}{c}\text { PEC with zero } \\
\text { thickness }\end{array}$ \\
\hline Metal & $3.5 \times 3.5$ \\
\hline Unit cell & 1.617 \\
\hline $\begin{array}{l}\text { In plane dimensions, }(\mathrm{P} \\
\times \mathrm{P})(\mathrm{mm} \text { ) }\end{array}$ & 9.702 \\
\hline $\begin{array}{l}\text { Thickness of the di- } \\
\text { electric layers, } \mathrm{s}(\mathrm{mm})\end{array}$ & $\mathrm{Lj} \times \mathrm{Lj} \mathrm{j}=1,4$ \\
\hline Total height, T (mm) \\
\hline $\begin{array}{l}\text { Metallization dimen- } \\
\text { sions }\end{array}$ \\
\hline $\begin{array}{l}\text { Patches in-plane } \\
\text { dimensions (mm2) }\end{array}$ \\
\hline $\begin{array}{l}\text { Strip loops widths } \\
(\mathrm{mm})\end{array}$ \\
\hline
\end{tabular}

TABLE III

SiZE OF SUBDOMAINS IN TERM OF WAVELENGTH AT $30 \mathrm{GHZ}$

\begin{tabular}{|l|c|}
\hline Lens unit cell & $0.35 \lambda \times 0.35 \lambda$ \\
\hline$(\mathrm{PxP})\left(\lambda^{2}\right)$ & $0.97 \lambda$ \\
\hline $\begin{array}{l}\text { lens unit cell height, T } \\
(\lambda)\end{array}$ & $\frac{\lambda}{200} \leq W_{j} \leq \frac{\lambda}{50}$ \\
\hline loops width, $L_{j}$ & $\frac{\lambda}{25} \leq L_{j} \leq \frac{\lambda}{4}$ \\
\hline patches width, $L_{j}$ & $0.35 \lambda \times 0.35 \lambda$ \\
\hline Air unit cell & $4 \lambda, 4.8 \lambda$ \\
\hline$(\mathrm{PxP})\left(\lambda^{2}\right)$ & \\
\hline $\begin{array}{l}\text { Air unit cell height, } \\
H_{1}, H_{2}(\lambda)\end{array}$ & $3.6 \lambda \times 3.15 \lambda$ \\
\hline Horn cell & \\
\hline $\begin{array}{l}\text { Aperture }\left(P_{h o r n} \times\right. \\
\left.Q_{h o r n}\right)\left(\lambda^{2}\right)\end{array}$ & $7.5 \lambda$ \\
\hline $\begin{array}{l}\text { Horn height, Thorn } \\
(\lambda)\end{array}$ & \\
\hline
\end{tabular}

Two 15-dBi standard-gain rectangular horn antennas are used to illuminate the transmit-array at each band (Flann Microwave $\mathrm{N}^{\circ} 2024015$ used for $20 \mathrm{GHz}$ and Flann Microwave $\mathrm{N}^{\circ} 2224015$ used for $30 \mathrm{GHz}$ ), with their phase centers positioned at a distance of $100 \mathrm{~mm}$ from the bottom face of the transmit-array. One horn orientation (y-pol) is used to simulate the response for each lens position (Fig. 1).

The TA is designed to produce a beam offset $\alpha_{0}=40^{\circ}$ for a focal distance $F=100 \mathrm{~mm}$ when the horn is aligned with the geometric center of the TA in the $x y$ plane. The top view of the lens is represented in Fig. 1. The aperture size is $196 \times$ $147 \mathrm{~mm}^{2}$ (Tab. IV). One should note that the TA is symmetric relative to the $x y$ plane. Elevation beam-scanning is produced by linear displacement of the TA (Fig. 1). This displacement is controlled by the parametric variable $a$. For this test, three TA positions are considered: $a=0 \mathrm{~mm}$ (corresponding to the center of the TA aligned with the feed phase center), $a=-15$ $\mathrm{mm}$ (TA moves to the right) and $a=44 \mathrm{~mm}$ (TA moves to left). Please note that the supporting structure shown in Fig. 1 was not considered in the simulation because it was confirmed that it has no significant effect on the antenna performance.

TABLE IV

DUAL-BAND TA ANTENNA

\begin{tabular}{|l|c|}
\hline TA & 100 \\
\hline Focal distance, F (mm) & $196 \times 147$ \\
\hline $\begin{array}{l}\text { In-plane dimensions } \\
\left(\mathrm{mm}^{2}\right)\end{array}$ & 2352 \\
\hline Number of unit cells & $40^{\circ}$ \\
\hline Beam direction $\left(^{\circ}\right)$ & $50^{\circ}$ \\
\hline $\begin{array}{l}\text { Without lens displace- } \\
\text { ment, } a=0 \mathrm{~mm}\end{array}$ & \\
\hline $\begin{array}{l}\text { Right lens } \\
\text { displacement, } a \quad= \\
-15 \mathrm{~mm}\end{array}$ \\
\hline $\begin{array}{l}\text { Left lens displacement, } \\
a=+44 \mathrm{~mm}\end{array}$ \\
\hline
\end{tabular}

The FETI-2LM numerical simulation of the dual-band TA is implemented on 9,601 Intel Xeon Broadwell E5-2680v4 processing cores of the Bull high-performance parallel machine "Occigen" of the "Centre Informatique National de l'Enseignement Superieur"(CINES). The configurations of the calculators used by the software packages CST and FACTOPO are specified in Tab. $\mathrm{V}$ and the problem sizes at $20 \mathrm{GHz}$ and $30 \mathrm{GHz}$ are specified in Tab. VI.

TABLE V

CONFIGURATIONS OF MACHINES USED

\begin{tabular}{|c|c|l|}
\hline Software & Method & Machine \\
\hline \multirow{2}{*}{ CST } & MLFMM & 2 Xeon Dual (E5-2620 V4@2.1 GHz), 8 cores \\
\hline FACTOPO & TLM & 2 Xeon Dual (E5-2620 V4@ 2.1 GHz), 8 cores \\
\hline
\end{tabular}

The simulations were carried out with MLFMM, TLM and FETI-2LM methods on meshes of different types and of very large sizes up to $6.2 \times 10^{10}$ tetrahedral cells (CST/TLM) and $2.26 \times 10^{9}$ edges (FETI-2LM) as indicated in Tab. VI. We can first observe that the results of the full-lens problem including the horn source were obtained with both CST methods on computers with 8 Xeon E5-2620V4 cores (MLFMM, TLM). 
TABLE VI

TA PROBLEM SIZE AT $\mathrm{F}=20 \mathrm{GHZ}$ AND $\mathrm{F}=30 \mathrm{GHZ}$

\begin{tabular}{|c|r|l|}
\hline Software & Method & Problem size \\
\hline \multirow{2}{*}{ CST } & MLFMM & $\begin{array}{l}20 \mathrm{GHz}: 6,80 \times 10^{5} \text { mesh cells } \\
30 \mathrm{GHz}: 1,36 \times 10^{6} \text { mesh cells }\end{array}$ \\
\hline \multirow{2}{*}{ FACTOPO } & TLM & $\begin{array}{l}20 \mathrm{GHz}: 5,50 \times 10^{10} \text { mesh cells } \\
30 \mathrm{GHz}: 6,20 \times 10^{10} \text { mesh cells }\end{array}$ \\
\hline
\end{tabular}

TABLE VII

COMPUTING RESOURCES AT F $=20 \mathrm{GHz}$ AND F $=30 \mathrm{GHz}$ (ONE BEAM)

\begin{tabular}{|c|c|c|c|}
\hline Software & Method & Elapse & Memory \\
\hline \multirow{2}{*}{ CST } & MLFMM & $\begin{array}{l}20 \mathrm{GHz}: 7 \mathrm{~h} 10 \mathrm{~m} \\
30 \mathrm{GHz}: 19 \mathrm{~h} 25 \mathrm{~m}\end{array}$ & $\begin{array}{l}20 \mathrm{GHz}: \text { RAM } 79 \mathrm{~GB} \\
30 \mathrm{GHz}: \text { RAM } 126 \mathrm{~GB}\end{array}$ \\
\hline & TLM & $\begin{array}{l}20 \mathrm{GHz}: 76 \mathrm{~h} 06 \mathrm{~m} \\
30 \mathrm{GHz}: 59 \mathrm{~h} 37 \mathrm{~m}\end{array}$ & $\begin{array}{l}20 \mathrm{GHz}: \text { RAM } 29 \mathrm{~GB} \text {, GPU } 10 \mathrm{~GB} \\
30 \mathrm{GHz} \text { RAM } 33 \mathrm{~GB} \text {, GPU } 12 \mathrm{~GB}\end{array}$ \\
\hline FACTOPO & FEM-FETI & $\begin{array}{l}20 \mathrm{GHz}: 45 \mathrm{~m} \\
30 \mathrm{GHz}: 45 \mathrm{~m}\end{array}$ & RAM peak/core : 2.5 GB \\
\hline
\end{tabular}

As illustrated in Fig. 2, the FETI-2LM domain decomposition method uses 9,601 subdomains (lens cells, air cells and horn cell) assigned to 9,601 cores Intel E5-2690V4. Indeed, the physical in-plane lens comprises $56 \times 42$ unitcells completed by 4 empty elementary cells of the same size all around the array in order to remove the absorbing boundary surface far away from the physical array $(1.4 \lambda)$. It gives an in-plane surface of $64 \times 50=3200$ cells of dimensions 3.5 $\mathrm{mm} \times 3.5 \mathrm{~mm} \times 9.702 \mathrm{~mm}$. Two layers comprising 3200 empty cells of height $H_{1}=40.25 \mathrm{~mm}$ and $H_{2}=48.61 \mathrm{~mm}$ are then introduced so as to place the horn at $F=100 \mathrm{~mm}$ from the lens. The total number of sub-domains is then $3 \times 3200$ $+1=9601$ (Fig.2).

The stop criterion in the time domain TLM solver is set to $-40 \mathrm{~dB}$. As a matter of fact, the TLM solver injects a transient pulse inside the structure via the port at the horns input, and the results in frequency domain are obtained by a classic Fourier Transform. The precision of the results is directly related to the amount of residual energy that is presented inside the calculation domain. The value of $-40 \mathrm{~dB}$ is the value of the residual energy that remains in the calculation domain. One should know that the energy is evacuated through three phenomena: radiated energy, reflected energy to the port (mismatch) and dissipated energy (losses).

The convergence of the 2 frequency domain methods (CST/MLFMM and FEM-FETI) is presented in Fig. 6 and Table. VIII where the gain patterns are plotted for a stopping criterion of $\epsilon=10^{-2}$ and $\epsilon=10^{-3}$ (residual norm $\frac{\|A x-b\|}{\|b\|}$ of the global linear system to be solved). It is observed that the level of the main lobe $\left(40^{\circ}\right)$ and reflection lobe (about $140^{\circ}$ ) is reasonably obtained with the FEM-FETI with a stopping criterion limited to $10^{-2}$ (orange curve) as the deviation is of $0.5 \mathrm{dBi}$ for the main lobe and $1.2 \mathrm{dBi}$ for the reflection lobe. Furthermore, the MLFMM convergence is not reached with a stopping criterion of $10^{-2}$ (green curve). Indeed, the level of the main lobe and reflection lobe is $10 \mathrm{dBi}$ lower than that obtained for a convergence of $10^{-3}$ (blue curve) and confirmed by the measurements (black curve).

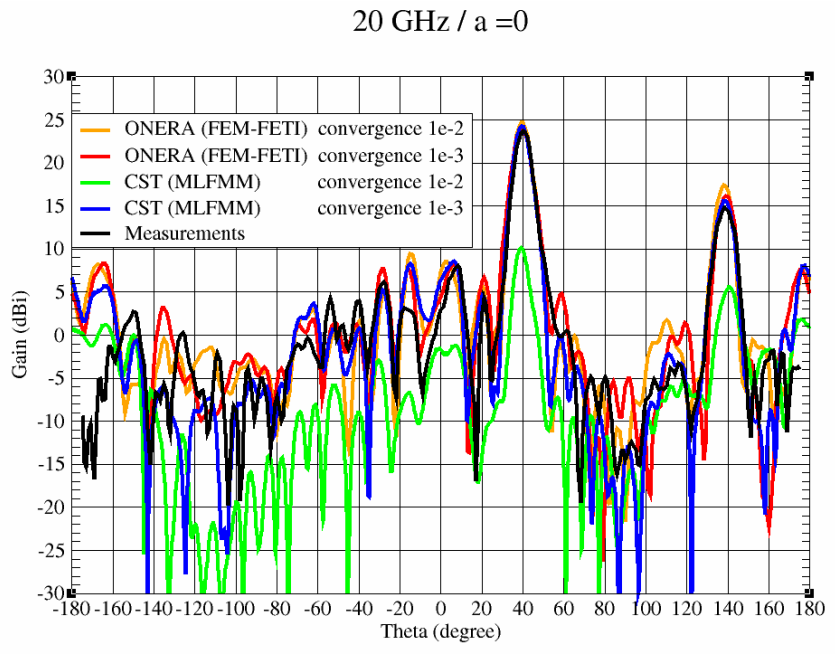

Fig. 6. Gain patterns convergence at $20 \mathrm{GHz}$ for position $a=0 \mathrm{~mm}$

TABLE VIII

MLFMM AND FEM-FETI CONVERGENCE AT $20 \mathrm{GHZ}$ FOR POSITION $a=0$ MM AND FOR $10^{-2}$ AND $10^{-3}$ CONVERGENCE

\begin{tabular}{|c|c|c|c|c|}
\hline \multirow{2}{*}{$\mathbf{F}=\mathbf{2 0 ~ G H z}$} & $\boldsymbol{\varepsilon}$ & \multicolumn{3}{|c|}{ Gain (dBi) } \\
\hline $\begin{array}{c}\text { Main lobe } \\
\left(40^{\circ}\right)\end{array}$ & $10^{-2}$ & 10,2 & 24.7 & 24.0 \\
\hline $\begin{array}{c}\text { Reflection lobe } \\
\left(140^{\circ}\right)\end{array}$ & $10^{-3}$ & 24.2 & 24.2 & 24.0 \\
\hline & $10^{-2}$ & 5.5 & 17.4 & 14.8 \\
\hline
\end{tabular}

In terms of memory we observe on Tab. VII and Tab. X that the FETI-2LM method is using 2.5 GBytes/core $\mathrm{x} 9601$ cores, that is, approximately 24 Terabytes of memory which is very much higher than the 39 GBytes of the TLM method or even the 79 GBytes of the MLFMM. This particularity comes from the fact that we have chosen to assign a computing core to each sub-domain even to those of smaller size located in the lens. A significant reduction in memory occupation could be obtained by allocating several sub-domains to a computing core as proposed in [21]. Finaly, we gain a factor of 10 in simulation time at $20 \mathrm{GHz}$ an a factor of 26 at $30 \mathrm{GHz}$ compared to the MLFMM, but the strategy for using the computational cores (which is not optimal here) for this FETI2LM simulation requires 303 more memory than MLFMM method. In terms of accuracy, the gain radiation patterns obtained with the Multilevel Fast Multiple Method (MLFMM) [1], the Transmission Line Modeling Method (TLM) [2] and the FETI-2LM, are considered to be globally comparable and acceptable compared to measurements as indicated by the cross comparisons in Fig. 7 and Fig. 8 for the main lobe $\left(\alpha_{0}=40^{\circ}\right)$ and the reflection lobe $\left(\alpha_{0}=140^{\circ}\right)$ of the TA. However, we can observe in Tab. IX fluctuations of around 1 $\mathrm{dBi}$ for the different solutions on the main lobe and reflection lobe for both frequencies $20 \mathrm{GHz}$ and $30 \mathrm{GHz}$, which attests to 
the difficulty of simulation of large-scale dual-band transmitarrays.

TABLE IX

SUMMARY OF SIMULATED AND MEASURED MAIN LOBE

\begin{tabular}{|c|c|c|c|c|c|}
\hline \multirow{2}{*}{ Freq. (GHz) } & \multirow{2}{*}{$\mathbf{a}(\mathbf{m m})$} & \multicolumn{4}{|c|}{ Gain (dBi) } \\
\cline { 2 - 6 } & -15 & 22.6 & 23.6 & 22.8 & 22.4 \\
\hline \multirow{2}{*}{20} & 0 & 24.2 & 24.7 & 24.2 & 24.0 \\
\hline \multirow{2}{*}{30} & +44 & 25.5 & 25.6 & 25.1 & 24.1 \\
\hline & -15 & 26.2 & 26.8 & 26.6 & 27.1 \\
\hline & 0 & 28.2 & 28.2 & 28.2 & 28.8 \\
\hline & +44 & 28.1 & 27.6 & 27.8 & 28.2 \\
\hline
\end{tabular}

TABLE $\mathrm{X}$

FETI-2LM COMPUTATIONAL STATISTICS

\begin{tabular}{|l|r|}
\hline Mesh parameters (unknowns) & \\
\hline Unit-cell sub-domain (average) & 432,539 \\
\hline Skeleton interface problem & 478 millions \\
\hline Total unknowns of the TA & 2.26 billion \\
\hline Simulation parameters & 9,601 \\
\hline Number of cores (Intel Xeon E5-2680v4) & 260 \\
\hline Number of iterations (interface problem) & $\epsilon=10^{-2}$ \\
\hline Stopping criterion & 45 minutes \\
\hline Elapse time (1 feed position) & 22.5 hours \\
\hline Elapse time (30 feed positions sequential) & 2 hours \\
\hline Elapse time (30 feed positions with block Krylov) & $2.5 \mathrm{~GB}$ \\
\hline Memory peak (per core) & \\
\hline
\end{tabular}

\section{PARALLEL COMPUTATION EFFICIENCY}

Tab. X shows the overall computational statistics observed for the FETI-2LM dual-band TA simulation. The multi-scale aspect of this domain decomposition simulation is shown in Tab. III and impacts significantly the FETI-2LM simulation. Indeed, we observe, for example that the height of the different types of subdomains varies between $0.97 \lambda$ (lens cell) and 7.5 $\lambda$ (horn cell). Likewise, the in-plane unit cell width varies between $0.35 \lambda$ (lens cell) and $3.6 \lambda$ (horn cell) and the width loop metallization is very thin $\left(\frac{\lambda}{200}\right)$. However, we can notice that the effort required to generate the mesh is quite limited. We need only to mesh a few sub-domains with the automatic procedure described previously in section. II. The complete mesh of the TA is indeed never built, which is a considerable advantage of the method.

TABLE XI

SUBDOMAINS UNKNOWNS RELATIVELY TO FIG. 2

\begin{tabular}{|l|c|}
\hline Subdomain & Unknowns \\
\hline Horn (cyan) & 678,704 \\
\hline Empty (green) & 227,979 \\
\hline Empty (purple) & 189,964 \\
\hline Average unit-cell (red) & 432,539 \\
\hline
\end{tabular}

As a consequence to the multi-scale nature of the problem to be solved, the number of unknowns in the sub-domains varies significantly up to $28 \%$ as shown in Tab. XI. It impacts the local matrix factorization time and the load balancing during
FETI-2LM simulations, which is far from perfect in all of the calculation steps (local matrix factorisation, upward/backward local resolutions in the subdomains, and iterative ORTHODIR resolution of the interface problem). Remember that the dimension of the skeleton interface problem is 478 million (Tab. $\mathrm{X})$. The iterative resolution of the interface problem requires, at each iteration, the resolution of the local problems as well as the exchange of the fields at the interfaces of all the subdomains. The imbalance of the local matrices factorizations and local problem solving phases (upward and backward substitutions) resulting from the different local mesh sizes then penalizes the convergence of the ORTHODIR method. This is due to the necessary syncronization of the core processors. Nevertheless, the computation times of 45 minutes for one beam attests the good level of parallelization of the method.

Even if the machines used are different from the ones indicated previously in section III, note that the FETI-2LM simulation time is much lower than that obtained with CST (19 hours and 25 minutes with the MLFMM and 59 hours and 37 minutes with the TLM at $30 \mathrm{GHz}$ ). To the best of our knowledge, the effectiveness and scalability of the TLM and MLFMM methods of CST has not been yet demonstrated on parallel machines with more than 9000 cores. Note also that the FETI-2LM method requires 20.5 hours by restarting from scratch for example if 30 beams are requested, but only 2 hours if using the block-Krylov recycling strategy (Tab. VII). It allows us to consider using it in the optimization phase of such type of TA.

Another very important point of the FETI-2LM method is its capability to be scaled for TA simulations which makes it a candidate for TAs of much higher gain. It has already been shown in [12], for example, that significantly increasing the size of periodic arrays has very little impact on the computation time. Indeed, Fig. 3 of reference [12] shows that the elapsed time per frequency observed for 4 metamaterial arrays with progressively increasing size $(22 \times 22,28 \times 28,56 \times 56$ and $85 \times 85)$ is only varying from 3 minutes $(0.3$ billion unknowns) to only 10 minutes (2.05 billion unknowns) on the Xeon Haswell cluster for a convergence lower than $10^{-3}$. This curve is linear and illustrates the good scalability of the method showing that increasing the number of sub-domains by a factor of 4 is increasing the simulation time by only 3 minutes. Recall that, when using the FEM, the occupation memory depends on the line bandwidth of the matrix (number of neighborhood edges of each edges of the mesh) and can vary considerably according to the regularity of the mesh. Our TA application has many areas with a large scale ratio which considerably affects the quality of the mesh and increases the bandwidth of the matrix. As a consequence it can lead in the sub-domains concerned to an increase of the required memory necessary for the local matrix factorization. Nevertheless, our domain decomposition implementation (number of unknowns in the sub-domain) is not optimal for this TA simulation. As a consequence we can optimize the use of the memory of each of the computational cores following the procedure recently proposed in [21] resulting in important savings in memory and computation time. Indeed, based on the Tab. XI, by increasing the number of unknowns in the sub-domains, it is possible 
to reduce the number of "lens" sub-domains by a factor of 2 ( 1 core allocated to 2 sub-domains) and by a factor of 4 the number of "air" sub-domains ( 1 core allocated to 4 subdomains) located between the horn and the lens. The total number of cores required for the TA simulation will then be: $1600+2 \times 800+1=3201$ and the memory required will be reduced to 8 Terabytes. Ka-band Geosynchronous Equatorial Orbit (GEO) satellites requires at least $40 \mathrm{dBi}$ gain antennas [9], corresponding to apertures of $60 \lambda$. To achieve a gain of this order we would need to scale 3 times the dimensions of the analysed dual-band TA. In this case, massive parallel computing is the only option to perform the full-wave analysis of these extremely electrical large structures. In fact, we can show as it follows that the presented infrastructure can deal with these large antennas without compromising the accuracy of the results. By extrapolation of our previous simulation results, the lens will be then made up of 22,188 unit-cells of width $3.5 \mathrm{~mm}$. Therefore, by using the optimized fill-in of the cluster with 1 core allocated to 2 "lens" sub-domains and one core allocated to 4 "air" sub-domains, the total number of cores for the full dual-band $40 \mathrm{dBi}$ TA simulation (lens and feed) will be 11, 094 (lens) $+33,182$ (air) +1 (horn) $=$ 44,377 . Consequently the memory required for this simulation is estimated to 111 Terabyte $(44,377 \times 25 \mathrm{~Gb})$. The simulation of the $40 \mathrm{dBi}$ dual-band TA is then reasonably accessible with the Occigen cluster already equipped with 50,544 cores.

\section{CONCLUSiON}

This work presents an application of the FETI-2LM Domain Decomposition Method to the calculation of highly complex transmit-array antennas in the Ka-band using FEM. The method is implemented on massively parallel clusters and a block-Krylov recycling algorithm is implemented in order to accelerate the TA simulation with mechanical beamsteering. The orientation of the beam is obtained by in-plane translation of the TA above the primary source, for a large number of beams. The simulation of all required TA positions is efficiently simulated with the FETI-2LM iterative method. An effective strategy based on the implementation of 3D non-periodic grids for fundamentally non-periodic applications with sub-domains of different scales is also proposed. Its main ingredient is the use of an automatic GID batch file procedure and $\mathrm{Tcl}$ scripts which allow the limited set of constitutive unit-cell of the TA to be meshed separately. Thus, the implementation of relatively fine meshes due to very fine details $\left(\frac{\lambda}{200}\right.$ at $\left.30 \mathrm{GHz}\right)$ in the sub-domains is rendered quite simple making unnecessary the sometimes very slow adaptive mesh refinement techniques. This work confirms the interesting performances in terms of accuracy and calculation time of the FETI-2LM domain decomposition methods in electromagnetism allowing relatively fast computation of transmitarrays gain radiation patterns for multiple beams. To the best of our knowledge, FETI-2LM methods had not previously been used for the simulation of complete transmit-array antennas with primary sources. We have also shown that the method can be used even when higher gains are required, as in the case of Geosynchronous Equatorial Orbit (GEO) satellite terminals (40 dBi), with apertures of $60 \lambda$.

\section{AKNOWLEDGMENTS}

The authors thank António Almeida and Carlos Brito from Instituto de Telecomunicações for prototype construction and measurements, Guillaume Dehan from ONERA for CAD and mesh generation and Enrique Escolano from CIMNE for relevant advice in GiD Tcl scripts and batch files.

\section{REFERENCES}

[1] J. M. Song, C. C. Lu, and W. C. Chew, "Multilevel fast-multiple algorithm for solving combined field integral equations of electromagnetic scattering," Compte rendu de lAcad. Sci., CR Phys., vol. 7, p. 474485, Sept 1995.

[2] C. Christopoulos, The Transmission Line Modeling Method: TLM. Piscataway, NY, IEEE Press, 1995.

[3] E. Lima, S. A. Matos, J. R. Costa, C. A. Fernandes, and N. J. G. Fonseca, "Circular polarization wide-angle beam steering at ka-band by in-plane translation of a plate lens antenna," IEEE Trans. Antennas and Propagation, vol. 63, no. 12, pp. 5443-5455, Dec 2015.

[4] S. A. Matos, E. Lima, J. S. Silva, J. R. Costa, C. A. Fernandes, N. J. G. Fonseca, and J. R. Mosig, "High gain dual-band beam-steering transmit array for satcom terminals at ka-band," IEEE Trans. Antennas and Propagation, vol. 65, no. 07, pp. 3528-3539, Jul 2017.

[5] H. Kaouach, L. Dussopt, J. Lanteri, T. Koleck, and R. Sauleau, "Wideband low-loss linear and circular polarization transmit-arrays in v-band," IEEE Trans. Antennas Propag., vol. 59, no. 7, pp. 2513-2523, July 2011.

[6] P. Naseri, S. Matos, J. Costa, and C. A. Fernandes, "A fast computational algorithm to evaluate large transmit-arrays,", European Conf. on Antennas and Propagation - EUCAP, April 2018.

[7] P. Naseri, S. Matos, E. Lima, J. Costa, C. A. Fernandes, and N. Fonseca, "Efficient evaluation of gradient transmit-arrays through an equivalent dispersive dielectric description," IEEE Trans. Antennas Propag., May 2019.

[8] D. M. Pozar, S. D. Targonski, and H. D. Syrigos, "Design of millimeter wave microstrip reectarrays," IEEE Trans. Antennas Propag., vol. 45, no. 2, p. 287296 , Februry 1997.

[9] "Satellite system characteristics to be considered in frequency sharing analysis between geostationay -satellite orbit (gso)," [online] Available, https : //www.itu.int/dms $s_{p}$ brec/itu $-\mathrm{r} / \mathrm{rec} / \mathrm{s} / \mathrm{R}-\mathrm{REC}-$ $S .1328-2-200001-S ! ! P D F-E . p d f$.

[10] S. Matos, J. Costa, C. A. Fernandes, and N. Fonseca, "Design of a $40 \mathrm{dbi}$ planar bifocal lens for mechanical beam steering at ka band," EUCAP conference, Paris, France, April 2016.

[11] F. Roux and A. Barka, FETI methods Chapter, Computational Electromagnetism - Recent advances and Engineering Applications. Springer, R. Mittra, 2014

[12] _ _ "Block krylov recycling algorithms for feti-2lm applied to threedimensional electromagnetic wave scattering and radiation,' IEEE Trans. Antennas and Propagation, vol. 65, no. 04, pp. 1886-1895, Apr 2017.

[13] "Grand equipement national en calcul intensif," [online] Available, http: / / www.genci.fr/fr/content/calculateurs-et-cent
"Partnership for advanced computing in europe," [online] Available, http: / / www.prace-ri.eu/prace-resources/.

[15] S. Varault, M. Soiron, A. Barka, A.-C. Lepage, and X. Begaud, "Rcs reduction with a dual polarized self-complementary connected array antenna," IEEE Trans. Antennas and Propagation, vol. 65, no. 2, pp. 567-575, February 2017.

[16] X. Begaud, S. Varault, M. Soiron, A.-C. Lepage, and A. Barka, "Ultrawideband and wide-angle microwave metamaterial absorber," Materials, vol. 11, no. 10, October 2018.

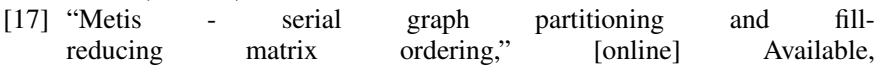
http: //glaros.dtc.umn. edu/gkhome/views/metis.

[18] M.-F. Xue and J.-M. Jin, "A hybrid conformal/nonconformal domain decomposition method for multi-region electromagnetic modeling," IEEE Trans. Antennas and Propagation, vol. 62, no. 4, pp. 2009-2021, Apr 2014.

[19] "Gid the personel pre and post processor," [online] Available, https://www.gidhome.com.

[20] "Tcl reference manual," [online] Available, https://www.http://tmml.sourceforge.net/doc/tcl/.

[21] A. Barka and A. Jouade, "Improvement of ddm preprocessing for the simulation of the graves radar densified sparse array for space surveillance and tracking," IEEE Antennas and Wireless Propagation Letters, vol. 19, no. 8, pp. 1434-1438, August 2020. 
[22] J. Jin, The Finite Element Method in Electromagnetics, 2nd ed. New York Wiley, 2002.

[23] "Cst microwave studio," [online] Available:, https://www. cst. com.

[24] "Ansys hfss," [online] Available:, https : / /www . ansys . com/products

[25] M. Vouvakis, Z. Zendes, and J. Lee, "A fem domain decomposition method for photonic and electromagnetic band gap structures," IEEE Trans. Antennas and Propagation, vol. 54, no. 10, pp. 3000-3009, Feb 2006.

[26] K. Zhao, V. Rawat, S. Lee, and J. Lee, "A domain decomposition method with nonconformal meshes for finite periodic and semi-periodic structures," IEEE Trans. Antennas and Propagation, vol. 55, no. 9, pp. 2559-2570, Sept 2007.

[27] "Intel mkl pardiso," 2015 , https://software.intel.com/en-us/node/470282.

[28] "Iterative methods for sparse linear systems," Yousef Saad [online] Available, https://www-users.cs.umn.edu/ saad/books.html.

[29] "workshop em-isae 2018," [online] Available, https://websites.isae-supaero.fr/workshop-em-isae-2d

[30] Z. Peng, M. B. Stephanson, and J. F. Lee, "Fast computation of angular responses of large-scale three-dimensional electromagnetic wave scattering," IEEE Trans. Antennas and Propagation, vol. 58, no. 9, pp. 3004-3012, Sept 2010.

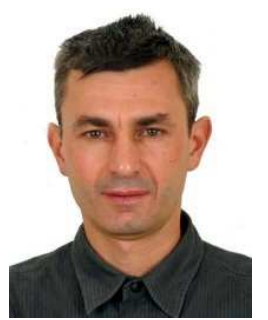

André Barka obtained the M.Sc, and Ph.D, degrees in applied mathematics from the University of Bordeaux, France, in 1986 and 1990 respectively. In 2008 he received his HDR "Habilitation à Diriger des Recherches" from the University of Toulouse and is a $\mathrm{PhD}$ Advisor for the GEET Doctoral School in Toulouse. André Barka is a Senior Scientist with over 20 years of research experience in computational electromagnetics (and especially in domain decomposition methods, in various application fields, such as Electromagnetic Compatibility, Radar Cross Section, and Antennas. He joined ONERA in 1989, and is in charge of developing advanced multi-domain and multi-method techniques combining integral equations, finite element methods and asymptotic techniques. He has been a member of the Board of the journal Computer Physics Communications since 2006, as computational electromagnetic specialist editor, and was work-package manager of advanced modeling activities in the FP6 IPAS European project and in the H2020 EPICEA European/Canadian project. From September 2016 to September 2017 he was an invited researcher at the Telecommunications institute of the University of Lisbon, Portugal, through a research convention with ONERA, the French DoD, and the University of Lisbon. Currently, his research activities include the design and realization of new antenna concepts based on meta-materials as well as advanced domain decomposition methods including Finite Element Tearing and Interconnecting (FETI) and Integral equation domain decomposition methods (IE-DDM).

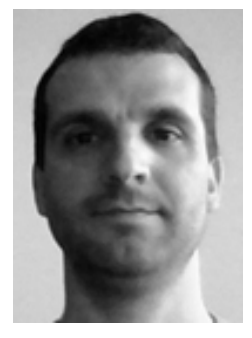

Sérgio A. Matos (S05M16) received the Licenciado, M.Sc., and Ph.D. degrees in electrical and computer engineering from Instituto Superior Técnico (IST), University of Lisbon, Lisbon, Portugal, in 2004, 2005, and 2010, respectively.

$\mathrm{He}$ is currently a Researcher with the Instituto de Telecomunicações (IT), Lisbon, Portugal. He is also an Assistant Professor at the Departamento de Ciências e Tecnologias da Informaçõ, Instituto Universitário de Lisboa(ISCTE-IUL). He is the coauthor of 80 technical papers in international journals and conference proceedings. His present research interests include electromagnetic wave propagation in metamaterials, flat-lens design and transmitarrays.

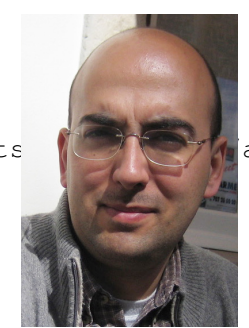

Jorge R. Costa (S97M03SM09) was born in Lisbon, Portugal, in 1974. He received the Licenciado and Ph.D. degrees in electrical and computer engineering from the Instituto Superior Técnico (IST), Technical ansWriversidy. of Lisbon, Lisbon, Portugal, in 1997 and 2002, respectively.

$\mathrm{He}$ is currently a Researcher at the Instituto de Telecomunicações, Lisbon, Portugal. He is also an Associate Professor at the Departamento de Ciências e Tecnologias da Informaçõ, Instituto Universitário de Lisboa (ISCTE-IUL). His present research interests include lenses, transmit-arrays, biomedical and RFID antennas. He is the coauthor of four patent applications and more than 200 contributions to peer reviewed journals and international conference proceedings. More than forty of these papers have appeared in IEEE Journals. Prof. Costa served as an Associate Editor for the IEEE Transactions on Antennas and Propagation from 2010 to 2016 and he was a Guest Editor of the Special Issue on Antennas and Propagation at mm- and Sub mm-Waves, from the IEEE Transactions on Antennas and Propagation, April 2013. He was the Co-Chair of the

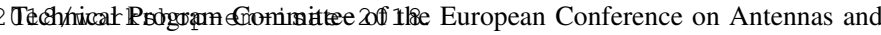
Propagation (EuCAP 2015) in Lisbon and General Vice-Chair of EuCAP 2017 in Paris.

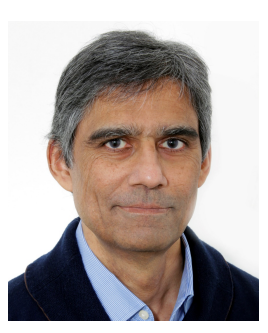

Carlos A. Fernandes (S86M89SM08) received the Licenciado, M.Sc., and Ph.D. degrees in electrical and computer engineering from Instituto Superior Técnico (IST), Technical University of Lisbon, Lisbon, Portugal, in 1980, 1985, and 1990, respectively. He joined IST in 1980, where he is presently a Full Professor with the Department of Electrical and Computer Engineering in the areas of microwaves, radio wave propagation, and antennas. He is a Senior Researcher with the Instituto de Telecomunicações and member of the Board of Directors. He has coauthored a book, three book chapters, more than 250 technical papers in peer reviewed international journals and conference proceedings, and seven patents in the areas of antennas and radio wave propagation modeling. His current research interests include antennas for millimeter-wave applications in 5G and satellite communications, RFID and UWB antennas for IoT, metamaterials, and medical microwave imaging. He was a Guest Editor of the Special Issue on Antennas and propagation at $\mathrm{mm}$ - and sub mmwaves of the IEEE TRANSACTIONS ON ANTENNAS AND PROPAGATION, April 2013.

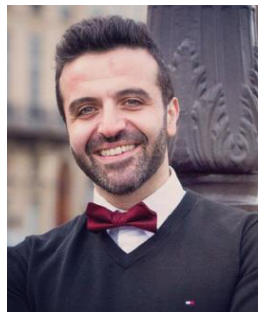

Hassan Chreim Hassan Chreim obtained his M.Sc and $\mathrm{PhD}$ degrees in Electronics and Electromagnetics from the university of Limoges in 2004 and 2006 respectively. He then spent 4 years in the university laboratory as a wireless engineer, where he worked on several projects with Thales, ESA, CNES. In 2014, he joined CST (computer Simulation Technology) as an application engineer, where he was a technical account manager and provided technical support in microwaves, thermal and low frequency related topics. He is now working in Dassault Systmes as territory technical manager for Africa and Middle east. 
$20 \mathrm{GHz} / \mathrm{a}=0$

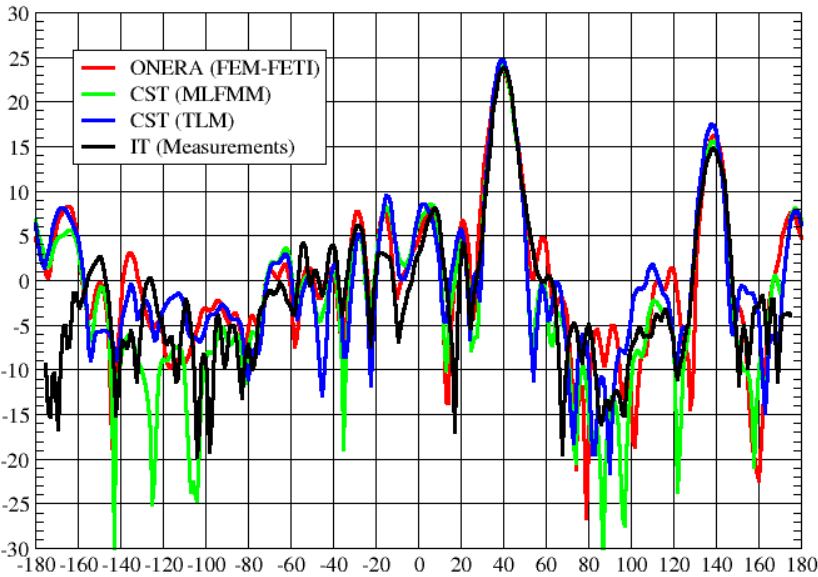

$20 \mathrm{GHz} / \mathrm{a}=-15$

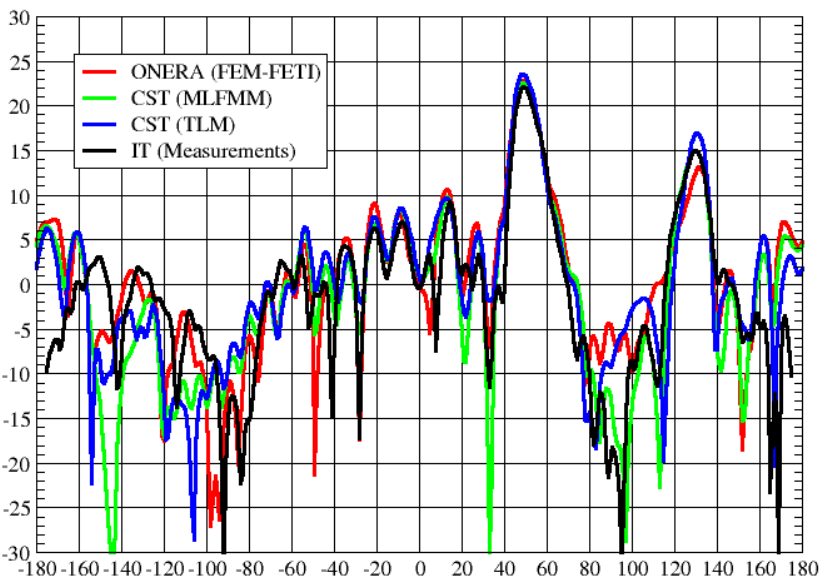

$20 \mathrm{GHz} / \mathrm{a}=+44$

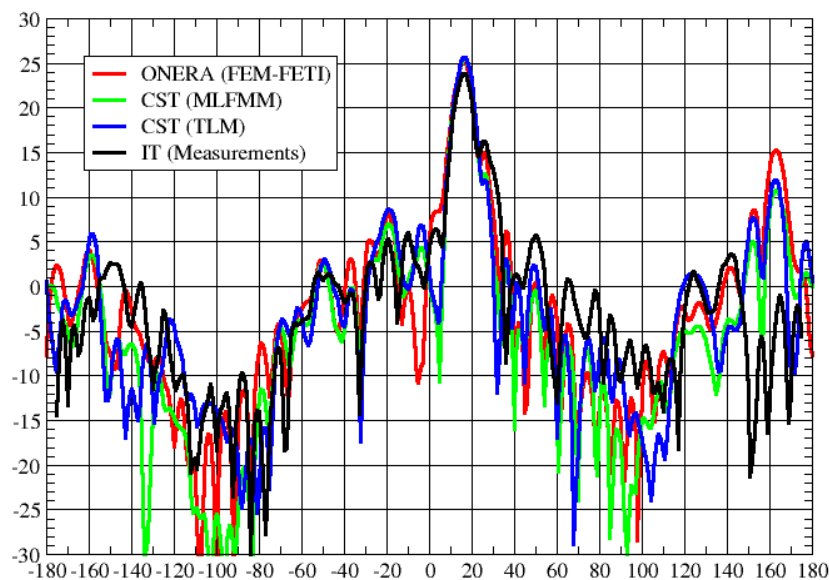

$30 \mathrm{GHz} / \mathrm{a}=0$

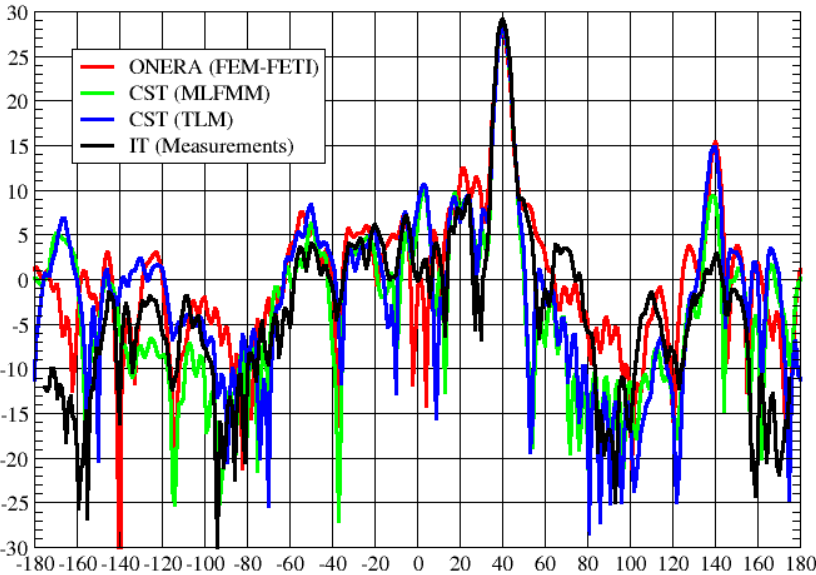

$30 \mathrm{GHz} / \mathrm{a}=-15$

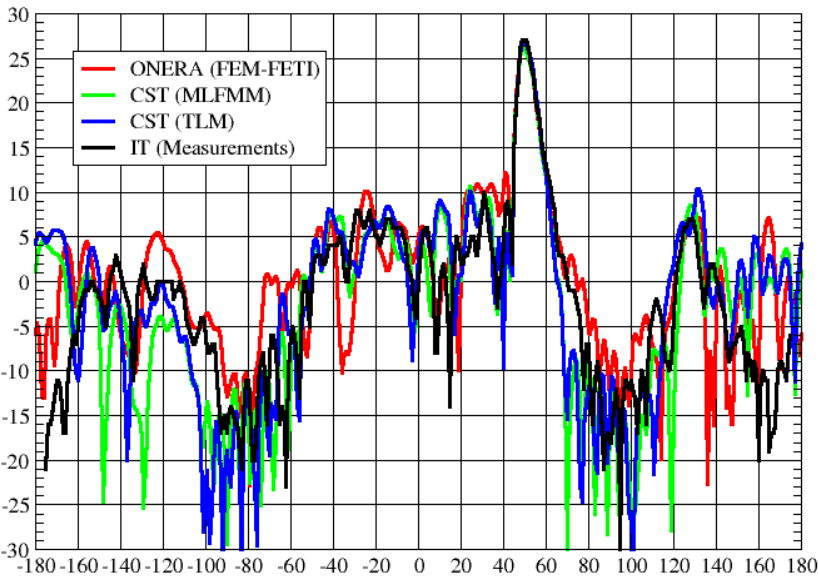

$30 \mathrm{GHz} / \mathrm{a}=+44$

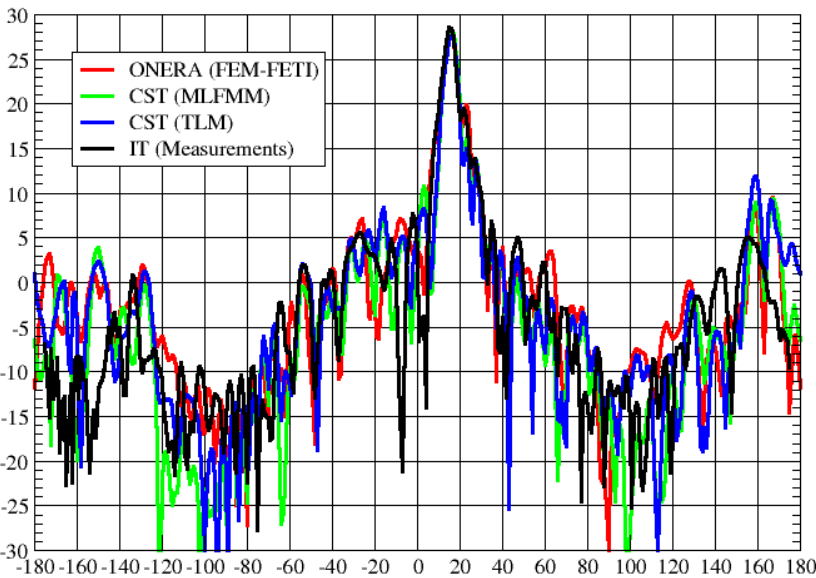

Fig. 7. Gain patterns at $20 \mathrm{GHz}$ for positions $a=0 \mathrm{~mm}, a=-15 \mathrm{~mm}$ and $a=+44$ $\mathrm{mm}$
Fig. 8. Gain patterns at $30 \mathrm{GHz}$ for positions $a=0 \mathrm{~mm}, a=-15 \mathrm{~mm}$ and $a=+44$ $\mathrm{mm}$ 